\title{
Evaluation of food photographs assessing the dietary intake of children up to 10 years old
}

\author{
Elisavet Valanou ${ }^{1}$, Androniki Naska ${ }^{1,2}$, Anastasia Barbouni ${ }^{1,3}$, Michael Katsoulis ${ }^{1}$, \\ Eleni Peppa ${ }^{1}$, Pavlos Vidalis ${ }^{1}$ and Antonia Trichopoulou ${ }^{1, *}$ \\ ${ }^{1}$ Hellenic Health Foundation, Kaisareias 13 \& Alexandroupoleos, GR-1 1527 Athens, Greece: ${ }^{2}$ Department of \\ Hygiene, Epidemiology and Medical Statistics, School of Medicine, National and Kapodistrian University of Athens, \\ Greece: ${ }^{3}$ Department of Public and Administrative Health, National School of Public Health, Athens, Greece
}

Submitted 5 July 2017: Final revision received 20 September 2017: Accepted 17 October 2017: First published online 4 December 2017

\begin{abstract}
Objective: Young children lack basic skills related to recognizing the types of foods they consume and dietary surveys often rely on parents' response. The present study aimed to evaluate how well parents of children aged from 3 months to 10 years perceive images of portions of foods commonly consumed by young children. Design: Pre-weighed, actual food portions ( $n$ 2314) were shown to the study participants who were asked to indicate the picture that corresponded to the food in view. Mean differences between picture numbers selected and shown were estimated and compared using unpaired $t$ tests or Tukey-Cramer pairwise comparisons.

Setting: Real-time testing of parents' perception of food images presenting portion sizes consumed by children up to 10 years old.

Subjects: A convenience sample of 138 parents/caregivers of young children (69\% females).

Results: Individuals selected the correct or adjacent image in about $97 \%$ of the assessments. Images presenting amorphous solids (i.e. pies and pastries with a filling), liquid or semi-liquid dishes (i.e. soups, porridges, fruit and vegetable purées) were more prone to bias. There was no indication that personal characteristics (gender, age, educational background, age, number of offspring) were associated with differences in the way parents/caregivers perceived the food pictures.

Conclusions: Food pictures may not be appropriate to quantify the intake of liquid, semi-liquid or amorphous solid foods in surveys addressing young children and studies evaluating their performance as food portion anchors should ensure the inclusion of several and various amorphous foods in the assessment.
\end{abstract}

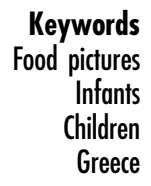

The methods used to quantify dietary intakes can be divided into those involving direct weighing of foods and those in which participants are asked to estimate their consumption through portion-size measurement aids, such as household measures, standard units, digital shapes, mounds and photographs ${ }^{(1)}$. Currently, nutritional assessment recommends the use of approaches which are of low respondent burden, such as food photographs ${ }^{(1-3)}$. The use of images has generally been acknowledged as reliable and easy, enhancing the accuracy of measurements, particularly in large-scale studies ${ }^{(4-7)}$. Food photographs can present various portions representative of the range of portion sizes usually consumed by the surveyed population and can be age-specific ${ }^{(8,9)}$.

The validity of using food photographs in portion size estimation has been studied in adults ${ }^{(5,10-18)}$, children ${ }^{(5,6,19-21)}$ and adolescents ${ }^{(5,6,18,19,22)}$. According to Nelson et al., food photographs can generally be evaluated in terms of the respondent's perception, conceptualization and memory ${ }^{(23)}$. Perception refers to a person's ability to relate a particular photograph to a food quantity that is actually presented. Conceptualization has been defined as the ability to develop a mental picture of an amount of food and to relate that to a photograph, and memory is the ability to accurately recall an amount of food consumed ${ }^{(24)}$.

All three components are expected to be affected by photograph characteristics (e.g. the number of different portions displayed; the size of each picture; the range of portion sizes; the interval between portion sizes; the order of presentation; the food's placement on the dish; the camera angle; lighting and colours; the volume and characteristics of the food, such as shape and firmness), as well 
as characteristics of the study participants ${ }^{(25,26)}$. For instance, children younger than 10-11 years old are not able to: (i) realize that the size of objects in a picture depends on their eye distance; (ii) recognize that the volume may remain the same when the dimensions of the object change (e.g. a tall thin can compared with a short broad can); and (iii) conceive a reverse action (e.g. imagine a liquid in its original bottle $)^{(2)}$. Furthermore, children are not familiar with all food names, common household measures and food preparation procedures. Thus, nutrition research often relies on parents' reports. Foster et al. reported that the parents of primary-school children were more accurate and precise in their estimates of intake than the children themselves ${ }^{(27)}$.

The Hellenic Health Foundation (HHF), coordinator of the Greek national health and nutrition survey (HYDRIA, http://www.hhf-greece.gr/hydria-nhns.gr/index_eng.html), developed a web-based application (the HHF Nutrition Tool) to collect intake information through $24 \mathrm{~h}$ recalls (adolescents and adults) or recording a food diary (children up to 10 years old). Making use of the US Department of Agriculture Automated Multiple Pass Method ${ }^{(28,29)}$, the HHF Nutrition Tool guides the respondent through a $24 \mathrm{~h}$ reference period, providing multiple different opportunities to recall and describe details of food and beverage intakes. The HHF Nutrition Tool's food list, facets and descriptors' system have been developed to accommodate the LanguaL $^{\mathrm{TM}}$ Food Description Thesaurus (http://www.langual. org/) and the FoodEx2 classification system of the European Food Safety Authority (http://www.efsa.europa.eu/ en/datex/datexfoodclass.htm). The HHF team further developed the tool's portion probes, including standard portions, household units and a food atlas including agespecific food pictures.

The present study aimed to assess how parents perceive the amount of food displayed in pictures taken to accommodate the eating habits of children up to 10 years old and to understand the net error introduced when the photographs are used to assess the children's dietary intake. All photographs were taken and developed under well-defined, standardized and controlled conditions.

\section{Methods}

Parents of children aged from 3 months to 10 years were selected using convenience sampling. Based on the average sample size of studies assessing the relative validity of food pictures for children ${ }^{(8,30)}$, the study aimed to include approximately 100 parents or caregivers of infants (3-11 months), toddlers (1-3 years) and children (4-10 years), representing the age and gender distribution of the country's child population (Census 2011 of the Hellenic Statistical Authority).

Eligible participants were recruited from the campus of the University of Athens Medical School located next to the two largest children's hospitals in the country, and from private paediatrician offices in different regions of the city. The study sample consisted of 138 parents/caregivers (forty-three males and ninety-five females), including university employees, students, hospital visitors and their relatives, as well as parents visiting the paediatrician. Participants did not have previous training on how to use portion-size measurement aids and were recruited to represent a range of educational backgrounds and sociodemographic characteristics, with an attempt to oversample females who are usually responsible for the child's feeding and avoid the inclusion of individuals in nutritionrelated professions. All subjects signed an informed consent before participation.

\section{The food atlas}

The photo atlas for children includes colour photographs of seventy-three series of simple foods (carrot portions, for instance) and recipes (e.g. vegetable stew), capturing the variability of local diets. The large majority (95\%) of the photo series present six portions in ascending order, with the smallest portion on the top left-hand side of each page. In the absence of data regarding children's portions in Greece, the selection of foods and dishes was based on the recommendations of international projects ${ }^{(31)}$, guidance documents of European bodies ${ }^{(3,32)}$, as well as the dietary intakes of about 3000 adults participating in the Greek national nutrition survey (HYDRIA 2013-14). In a study assessing associations between the amounts served to and consumed by children and the amounts that their parents served themselves, Johnson et al. reported strong correlations between portions offered by caregivers and the amounts children consumed with a mean difference of approximately $20 \%$ in energy intake between adults and their children ${ }^{(33)}$. Based on these findings, the 5th and 95th centiles of the intakes reported by Greek adults in 2013-14 were reduced by $20 \%$ and corresponded to the quantities presented in the first and last picture in each photo series. The quantities presented in the intermediate pictures were estimated using equal increments on a log scale, based on the Weber-Fechner general psychophysical law ${ }^{(27,34)}$.

Foods were displayed on two different types of plate (flat plates and bowls) of common white colour and no pattern. At the left and right of plates, a spoon, fork and knife were placed to serve as size reference. Photographs were taken by a professional photographer in a $60 \mathrm{~cm} \times 60 \mathrm{~cm} \times 60 \mathrm{~cm}$ photo studio (i.e. a cubic photo tent softening and reflecting the light). A rig of two Dr Fishcer $400 \mathrm{~W}$ lamps with diffusers for soft shadows was used to create optimal lighting conditions. The focus distance was $70 \mathrm{~mm}$ and the lens used was a Sigma $70-300 \mathrm{~mm}$ with shutter speed of $0.5 \mathrm{~s}$ and aperture set at $\mathrm{f} / 22$. The lens was placed at three viewing angles: $45^{\circ}$ for spreads on slices of bread, $35^{\circ}$ for cakes (to ensure capturing both height and width) and $52^{\circ}$ for all other foods and dishes, including breakfast cereals.

The printed images were colour digital with the size of $89 \mathrm{~mm} \times 60 \mathrm{~mm}$, allowing six photos to be 
displayed on a page. Portions appeared in a sequence of smallest to largest, the name (in Greek) was shown on the top of each series, but with no indication on the food weight displayed.

\section{Study design}

The study aimed to evaluate the perception of seventythree series of food photographs commonly consumed by the Greek child-age population. Each photo series was evaluated through pre-weighed portions of foods that were shown to study participants. In particular, three different quantities were defined per picture: the middle quantity (Q2) corresponded exactly to the quantity presented in the image; the first (Q1) and the last quantities (Q3) were defined on the basis of Q2 and were somewhat smaller (Q1) or larger (Q3) than Q2. Specifically, Q1 was calculated as Q2 minus one-third of the gram difference between the quantity of the image to be evaluated and the preceding one; and, proportionally, Q3 was defined as Q2 plus one-third of the gram difference between the quantity of the evaluated image and the following one ${ }^{(18)}$.

Pre-weighed actual portions of various foods were displayed and participants were asked to indicate which food picture in the book best corresponded to the actual portion on the plate. In general, each of the eighteen portions corresponding to the six images included in a series was evaluated twice. In accordance with similar evaluations $^{(15-17,30,33)}$, the food items displayed by session and the portions presented to study participants were randomly allocated, in order to avoid any pattern in participants' replies, as well as to prevent contamination from one session to the other. In addition, the staff were instructed not to include more than two portions of the same food in one individual session so that the different portions of each picture series would be evaluated by at least eighteen individuals. In total, 2314 pre-weighed, actual portions were shown to the study participants, corresponding to an average of seventeen portions per participant. The session was concluded with the introduction of a brief evaluation questionnaire aiming to assess participants' views on the quality and applicability of the photo series.

\section{Statistical analysis}

The pictures in each series were numbered from 1 (smallest) to 6 (largest amount) and replies were evaluated through calculating mean (SD) differences between the picture number which the respondents indicated and the picture number corresponding to the portion which was actually shown. Differences were compared using $t$ tests. Since participants could not select a precedent to picture No1 or a subsequent to picture No6 image, the performance of pictures No1 and No6 was evaluated through estimating the distribution of correct, adjacent or distal selections, considering a random error of \pm 1 photo selection as acceptable ${ }^{(21)}$. For the presentation of results, the seventy-three photo series were organized into twelve groups (Table 1). The effect of the type of food and parents' personal characteristics on their selections was evaluated through unpaired $t$ tests (gender and years of schooling) or through Tukey-Kramer pairwise comparisons (type of food, age, number and age of offspring). All analyses were performed using the Stata statistical software package release 11 .

\section{Results}

The personal characteristics of the study participants by number of offspring are presented in Table 2. By study design, the sample included more women than men $(69 \%$ females) and young adults (79\% were between 25 and 44 years of age), since having at least one child aged between 3 months and 10 years was the primary inclusion criterion. Among both genders, most parents/caregivers (87\% overall, $91 \%$ of males and $85 \%$ of females) had either one

Table 1 Classification of foods and dishes included in the present study

\begin{tabular}{|c|c|c|}
\hline Main category & $\begin{array}{l}\text { No. of dishes } \\
\text { (picture series) }\end{array}$ & Foods and dishes included \\
\hline Vegetables and legumes & 15 & $\begin{array}{l}\text { Cucumber, tomato, carrot, green leafy vegetables (raw or boiled), cabbage, broccoli, } \\
\text { beans and peas, stuffed vegetables with rice, spinach with rice, vegetable stew, } \\
\text { vegetable purée }\end{array}$ \\
\hline Spreads & 4 & Marmalade, jam and butter \\
\hline Cereals and cereal-based dishes & 16 & $\begin{array}{l}\text { Bread, pasta (plain boiled, different patterns including traditional ones), macaroni pie, } \\
\text { rice, trahanas (traditional porridge), breakfast cereals, porridge }\end{array}$ \\
\hline Sweets & 5 & Cakes, sweet pies with cream fillings \\
\hline Meat and meat-based dishes & 11 & $\begin{array}{l}\text { Meat in lemon sauce, soup of meat balls with rice, meat balls, bolognaise sauce, } \\
\text { steaks, silverside slices, roasted chicken, sausages, burgers }\end{array}$ \\
\hline Seafood & 4 & Fish (whole or fillet), fried squid \\
\hline Fruit & 3 & Melon, fruit purée, fruit compote \\
\hline Dairies and eggs & 5 & Cream pudding, rice pudding, ice cream, tzatziki, egg omelette \\
\hline Potatoes & 4 & French fries, baked potatoes, potato purée, chips \\
\hline $\begin{array}{l}\text { Traditional pies and savoury } \\
\text { pastries }\end{array}$ & 3 & Spinach pies (triangular, rectangular), pizza \\
\hline Soups & 1 & Vegetable soup \\
\hline Cheese & 2 & Feta cheese and different varieties of traditional yellow cheeses \\
\hline
\end{tabular}


or two children (the fertility ratio in Greece is equal to 1.4 children per woman aged 15-49 years) and about 30\% of the study participants had not pursued higher education. Of note, participants with a lower educational level were more frequently parents of two or more children.

Table 3 presents the number of assessments performed and the mean differences in selections for pictures No2 to No5 per food group. A negative difference indicates the selection of a picture corresponding to a smaller quantity than the one actually shown on the plate and, correspondingly, a positive difference indicates the opposite. Providing that the food portion served on the plate represents the 'true quantity', negative differences point to

Table 2 Descriptive characteristics of the study participants, a convenience sample of Greek parents/caregivers $(n$ 138) of children aged 3 months to 10 years, by number of offspring

\begin{tabular}{|c|c|c|c|c|c|c|c|c|}
\hline & \multicolumn{6}{|c|}{ Number of offspring } & & \\
\hline & \multicolumn{2}{|c|}{ One } & \multicolumn{2}{|c|}{ Two } & \multicolumn{2}{|c|}{$\begin{array}{c}\text { Three or } \\
\text { more }\end{array}$} & \multicolumn{2}{|c|}{ Total } \\
\hline & $n$ & $\%$ & $n$ & $\%$ & $n$ & $\%$ & $n$ & $\%$ \\
\hline $\begin{array}{l}\text { Overall } \\
\text { Gender }\end{array}$ & 49 & 36 & 71 & 51 & 18 & 13 & 138 & 100 \\
\hline Male & 13 & 9 & 26 & 19 & 4 & 3 & 43 & 31 \\
\hline Female & 36 & 26 & 45 & 33 & 14 & 10 & 95 & 69 \\
\hline \multicolumn{9}{|c|}{ Education (years of schooling) } \\
\hline$\leq 12$ & 7 & 5 & 23 & 17 & 10 & 7 & 40 & 29 \\
\hline$>12$ & 42 & 30 & 48 & 35 & 8 & 6 & 98 & 71 \\
\hline \multicolumn{9}{|c|}{ Age (years) } \\
\hline $25-34$ & 17 & 12 & 12 & 9 & 1 & 1 & 30 & 22 \\
\hline $35-44$ & 22 & 16 & 46 & 33 & 11 & 8 & 79 & 57 \\
\hline$\geq 45$ & 10 & 7 & 13 & 9 & 6 & 4 & 29 & 21 \\
\hline
\end{tabular}

images that led individuals to perceive the food quantity in the picture as larger than it actually was. Consequently, positive differences indicate images that led individuals to perceive the quantity in the picture as smaller than it actually was. Mean differences were more frequently zero or negative than positive and never exceeded one, suggesting that participants generally tended to select the correct or its adjacent portions. Overall, in $69 \%$ of the assessments participants pointed to the correct image and in $97 \%$ of the assessments they selected either the correct picture or its preceding or subsequent picture. Differences varied and were generally not significant. Exceptions were the pictures presenting 'vegetable soup' (differences were constantly negative, although not significant); 'vegetables and legumes' (differences were negative and significant); 'traditional pies and other savoury pastries' (differences were positive, although not significant); and pictures No4 and No5 of the 'dairies and eggs' (negative differences, but not significant). Results point to a possibility for an underestimation of the consumed quantity of 'vegetables and legumes' (including soups) and an overestimation of the consumed quantity of 'traditional pies and savoury pastries', if these pictures were used to quantify dietary intake in a survey setting.

Table 4 presents the frequency with which participants pointed to the correct, adjacent or distal pictures when they were presented with actual quantities corresponding to photo No1 or No6. For all food groups, participants indicated the correct or an adjacent picture in more than $80 \%$ of the assessments. However, the percentage of individuals who indicated an adjacent or more distal picture was higher in the case of picture No1 of the 'potatoes' and picture No6

Table 3 Number of assessments $(n)$ and differencest, mean and SD, between the picture number selected by each participant and the picture number corresponding to the actually displayed portion (pictures No2-No5 in all photo series) $\ddagger$; study participants are a convenience sample of Greek parents/caregivers $(n 138)$ of children aged 3 months to 10 years

\begin{tabular}{|c|c|c|c|c|c|c|c|c|c|c|c|c|}
\hline \multirow[b]{3}{*}{ Food group } & \multicolumn{3}{|c|}{$\begin{array}{c}\text { Picture No2 } \\
\text { (overall: mean } \\
\text { difference }=-0.002 \text {, } \\
S D=0.743 \text { ) }\end{array}$} & \multicolumn{3}{|c|}{$\begin{array}{c}\text { Picture No3 } \\
\text { (overall: mean } \\
\text { difference }=-0.108 \text {, } \\
S D=0.681 \text { ) }\end{array}$} & \multicolumn{3}{|c|}{$\begin{array}{c}\text { Picture No4 } \\
\text { (overall: mean } \\
\text { difference }=-0.161 \text {, } \\
S D=0.651 \text { ) }\end{array}$} & \multicolumn{3}{|c|}{$\begin{array}{c}\text { Picture No5 } \\
\text { (overall: mean } \\
\text { difference }=-0 \cdot 192, \\
S D=0.649 \text { ) }\end{array}$} \\
\hline & \multirow[b]{2}{*}{$n$} & \multicolumn{2}{|c|}{ Difference } & \multirow[b]{2}{*}{$n$} & \multicolumn{2}{|c|}{ Difference } & \multirow[b]{2}{*}{$n$} & \multicolumn{2}{|c|}{ Difference } & \multirow[b]{2}{*}{$n$} & \multicolumn{2}{|c|}{ Difference } \\
\hline & & Mean & $\mathrm{SD}$ & & Mean & SD & & Mean & SD & & Mean & SD \\
\hline Vegetables and legumes & 82 & $-0.27^{\star \star \star}$ & 0.57 & 84 & $-0.32^{\star \star \star}$ & 0.66 & 84 & $-0.39^{\star \star \star}$ & 0.73 & 80 & $-0.33^{\star \star *}$ & 0.59 \\
\hline Spreads & 19 & -0.05 & 0.62 & 20 & 0.05 & 0.60 & 27 & -0.07 & 0.47 & 26 & $-0 \cdot 15$ & 0.67 \\
\hline Cereals and cereal-based dishes & 81 & 0.14 & 0.96 & 83 & $-0.29^{\star \star}$ & 0.77 & 81 & $-0 \cdot 17^{*}$ & 0.77 & 79 & $-0 \cdot 16^{*}$ & 0.67 \\
\hline Sweets & 30 & 0.00 & 0.59 & 28 & -0.07 & 0.94 & 28 & -0.18 & $0 \cdot 72$ & 30 & -0.30 & 1.02 \\
\hline Meat and meat-based dishes & 52 & 0.00 & 0.69 & 52 & 0.12 & 0.43 & 54 & 0.09 & 0.40 & 49 & -0.06 & 0.32 \\
\hline Seafood & 20 & 0.00 & 0.00 & 19 & -0.11 & 0.32 & 19 & 0.05 & 0.40 & 19 & -0.05 & $0 \cdot 23$ \\
\hline Fruit & 18 & -0.06 & $0 \cdot 24$ & 16 & -0.13 & 0.50 & 16 & -0.19 & 0.54 & 17 & -0.18 & 0.64 \\
\hline Dairies and eggs & 26 & 0.00 & $0 \cdot 75$ & 30 & -0.03 & 0.41 & 29 & -0.21 & 0.62 & 28 & $-0.36^{\star}$ & 0.83 \\
\hline Potatoes & 24 & $0 \cdot 38^{* *}$ & 0.58 & 21 & 0.19 & 0.75 & 23 & -0.17 & 0.58 & 21 & 0.00 & 0.55 \\
\hline Traditional pies and savoury pastries & 18 & 0.17 & $0 \cdot 86$ & 17 & 0.12 & 0.60 & 18 & 0.11 & 0.32 & 18 & 0.00 & 0.49 \\
\hline Soups & 6 & -1.00 & 0.00 & 6 & -0.50 & 0.55 & 6 & -0.67 & 1.03 & 6 & -0.83 & $1 \cdot 17$ \\
\hline Cheese & 11 & 0.55 & $1 \cdot 29$ & 12 & 0.50 & 0.80 & 12 & -0.08 & 0.51 & 12 & 0.00 & 0.43 \\
\hline
\end{tabular}

${ }^{*}$ Significant difference at $5 \%$ level of significance.

${ }^{* *}$ Significant difference at $1 \%$ level of significance.

*** Significant difference at $0.1 \%$ level of significance.

†Differences estimated as (picture number selected)-(picture number of the displayed, actual portion).

fLevel of significance of estimated differences evaluated through a $t$ test. 
Table 4 Number $(n)$ and percentage (\%) of selections of correct, adjacent or distal† food pictures (picture No1 and picture No6 in all photo series); study participants are a convenience sample of Greek parents/caregivers $(n 138)$ of children aged 3 months to 10 years

\begin{tabular}{|c|c|c|c|c|c|c|c|c|c|c|c|c|c|c|}
\hline \multirow[b]{3}{*}{ Food group } & \multicolumn{7}{|c|}{ Picture No1 } & \multicolumn{7}{|c|}{ Picture No6 } \\
\hline & \multirow{2}{*}{$\frac{\text { All }}{n}$} & \multicolumn{2}{|c|}{$\begin{array}{c}\text { No } \\
\text { difference }\end{array}$} & \multicolumn{2}{|c|}{$\begin{array}{l}\text { Exactly } 1 \text { picture } \\
\text { difference } \\
\end{array}$} & \multicolumn{2}{|c|}{$\begin{array}{l}>1 \text { picture } \\
\text { difference }\end{array}$} & \multirow{2}{*}{$\frac{\text { All }}{n}$} & \multicolumn{2}{|c|}{$\begin{array}{c}\text { No } \\
\text { difference }\end{array}$} & \multicolumn{2}{|c|}{$\begin{array}{l}\text { Exactly } 1 \text { picture } \\
\text { difference }\end{array}$} & \multicolumn{2}{|c|}{$\begin{array}{l}>1 \text { picture } \\
\text { difference }\end{array}$} \\
\hline & & $n$ & $\%$ & $n$ & $\%$ & $n$ & $\%$ & & $n$ & $\%$ & $n$ & $\%$ & $n$ & $\%$ \\
\hline Vegetables and legumes & 86 & 66 & 77 & 17 & 20 & 3 & 3 & 78 & 39 & 50 & 35 & 45 & 4 & 5 \\
\hline Spreads & 17 & 13 & 76 & 4 & 24 & 0 & 0 & 24 & 22 & 92 & 1 & 4 & 1 & 4 \\
\hline Cereals and cereal-based dishes & 75 & 54 & 72 & 17 & 23 & 4 & 5 & 79 & 51 & 65 & 20 & 25 & 8 & 10 \\
\hline Sweets & 30 & 26 & 87 & 4 & 13 & 0 & 0 & 28 & 24 & 86 & 4 & 14 & 0 & 0 \\
\hline Meat and meat-based dishes & 50 & 46 & 92 & 2 & 4 & 2 & 4 & 45 & 38 & 84 & 7 & 16 & 0 & 0 \\
\hline Seafood & 20 & 20 & 100 & 0 & 0 & 0 & 0 & 20 & 19 & 95 & 1 & 5 & 0 & 0 \\
\hline Fruit & 17 & 13 & 76 & 4 & 24 & 0 & 0 & 18 & 14 & 78 & 4 & 22 & 0 & 0 \\
\hline Dairies and eggs & 27 & 22 & 81 & 5 & 19 & 0 & 0 & 26 & 18 & 69 & 5 & 19 & 3 & 12 \\
\hline Potatoes & 23 & 14 & 61 & 8 & 35 & 1 & 4 & 24 & 17 & 71 & 7 & 29 & 0 & 0 \\
\hline Traditional pies and savoury pastries & 17 & 17 & 100 & 0 & 0 & 0 & 0 & 18 & 18 & 100 & 0 & 0 & 0 & 0 \\
\hline Soups & 6 & 6 & 100 & 0 & 0 & 0 & 0 & 6 & 4 & 67 & 1 & 17 & 1 & 17 \\
\hline Cheese & 11 & 8 & 73 & 2 & 18 & 1 & 9 & 12 & 11 & 92 & 0 & 0 & 1 & 8 \\
\hline
\end{tabular}

†'Correct' corresponds to selections of pictures of the displayed portions; 'adjacent' corresponds to selections of picture No2, when the quantity in picture No1 was displayed, or selections of picture No5, when the quantity in picture No6 was displayed; and 'distal' refers to any other selection.

of the 'vegetables and legumes' photo series. In contrast to photos No2-No5 of the series presenting 'traditional pies and savoury pastries', the two borderline photos (No1 and No6) allowed an accurate perception of the quantity displayed.

We additionally estimated the frequency of correct replies for all pictures in each series. Images of very small or very large portions performed better than the intermediate ones in the case of 'cereals and cereal-based dishes', 'sweets' and 'spreads'. For all other food groups there was no consistent pattern in correct replies and we confirmed our previous finding that certain pictures presenting 'potatoes', 'vegetables and legumes' (including soups) and 'dairies and eggs' led participants to misjudge the portion presented. Moreover, we estimated the percentage frequency of correct selections by actual portion displayed, to assess whether participants who were presented with food quantity equal to the one of the image $(\mathrm{Q} 2)$ selected the correct image more often than other participants presented with quantities somewhat smaller (Q1) or larger (Q3) than the one in the image. We noted that the percentage of correct replies varied among pictures and actual portions (data not shown). Nevertheless, this analysis again confirmed that participants encountered more difficulties in quantifying amorphous foods and liquid or semi-liquid dishes than solid foods. Hence, actual portions of soups, porridges, fruit and vegetable purées, as well as pies with various fillings were more frequently misclassified.

Table 5 describes mean differences between picture numbers by participants' characteristics and food group. In almost all cases, mean differences were negative, but close to zero. There was no indication that personal characteristics (gender, age and educational background) were associated with differences in the way parents/caregivers perceived the food pictures. Furthermore, the way parents perceived the food quantities presented in the pictures was not associated with the number and age of their offspring. Regarding differences by food groups, the pictures of 'vegetables and legumes' led respondents to perceive the quantity displayed as larger than it really was; in a survey setting, this may lead to an underestimation of the true intake. Somewhat larger mean differences in perception were also observed in the cases of 'soups' and 'cheese', but the number of assessments was small (up to twelve assessments per picture).

\section{Discussion}

In a study to evaluate how well parents and caregivers of children aged 3 months to 10 years perceive food pictures, we noted that in most cases (69\%) the food pictures allowed an accurate perception of the quantity presented. Parents and caregivers, however, encountered difficulties in perceiving the quantities of 'vegetables and legumes' (including soups), 'traditional pies and savoury pastries' and 'cheese', although a small number of assessments were performed in relation to the latter category. The majority of participants $(90 \%)$ considered the use of the food atlas easy or relatively easy and only 3\% found the process relatively difficult or difficult (data not shown). When participants were asked to report which foods were more difficult to quantify, they indicated dishes of 'dairies and eggs' and 'soups'. The quantification of 'meat and meat-based dishes' was reported as the easiest.

Our findings agree well to those of similar studies in children and adolescents. In a study among individuals aged 9-19 years, Lillegaard et al. reported that the correct portion was selected in $60 \%$ of the measurements when participants were asked to correspond a portion size 
Table 5 Mean differences in picture selectiont by participants' characteristics and food group; study participants are a convenience sample of Greek parents/caregivers ( $n$ 138) of children aged 3 months to 10 years

\begin{tabular}{|c|c|c|}
\hline & Mean difference & Significant differences $\ddagger$ \\
\hline \multicolumn{3}{|l|}{ Gender§ } \\
\hline Male & -0.11 & NS \\
\hline Female & -0.09 & NS \\
\hline \multicolumn{3}{|c|}{ Education (years of schooling)§ } \\
\hline$\leq 12$ & -0.12 & NS \\
\hline$>12$ & -0.08 & NS \\
\hline \multicolumn{3}{|l|}{ Age group (years) $\|$} \\
\hline $25-34$ & -0.12 & NS \\
\hline $35-44$ & -0.07 & NS \\
\hline$\geq 45$ & $-0 \cdot 12$ & NS \\
\hline \multicolumn{3}{|c|}{ Number of offspring $\|$} \\
\hline 1 & -0.08 & NS \\
\hline 2 & $-0 \cdot 11$ & NS \\
\hline 3 or more & -0.04 & NS \\
\hline \multicolumn{3}{|c|}{ Age group of child (years) $\|$} \\
\hline$<1$ & -0.11 & NS \\
\hline $1-3$ & -0.09 & NS \\
\hline$\geq 4$ & -0.09 & NS \\
\hline \multicolumn{3}{|l|}{ Food group $\|$} \\
\hline $\begin{array}{l}\text { Vegetables and } \\
\text { legumes }\end{array}$ & $-0 \cdot 26$ & $\begin{array}{l}\text { with spreads, cereals, meat, } \\
\text { fish, potatoes, pastries, cheese }\end{array}$ \\
\hline Spreads & -0.05 & with vegetables, soups \\
\hline $\begin{array}{l}\text { Cereals and } \\
\text { cereal-based } \\
\text { dishes }\end{array}$ & $-0 \cdot 11$ & vegetables, soups, cheese \\
\hline Sweets & -0.09 & with soups, cheese \\
\hline $\begin{array}{l}\text { Meat and meat- } \\
\text { based dishes }\end{array}$ & 0.02 & with vegetables, soups \\
\hline Seafood & -0.03 & with vegetables, soups \\
\hline Fruit & -0.09 & with soups \\
\hline $\begin{array}{l}\text { Dairies and } \\
\text { eqgs }\end{array}$ & $-0 \cdot 14$ & with soups, cheese \\
\hline Potatoes & 0.09 & with vegetables, soups \\
\hline $\begin{array}{l}\text { Traditional pies } \\
\text { and savoury } \\
\text { pastries }\end{array}$ & 0.07 & with vegetables, soups \\
\hline Soups & -0.58 & $\begin{array}{l}\text { with all food groups except for } \\
\text { vegetables }\end{array}$ \\
\hline Cheese & 0.21 & $\begin{array}{l}\text { with vegetables, cereals, } \\
\text { sweets, dairy products, soups }\end{array}$ \\
\hline
\end{tabular}

†Differences estimated as (picture number selected)-(picture number of the displayed, actual portion).

$\ddagger$ The detected significant differences across groups were defined by $P<0.05$, when using the Tukey-Kramer test.

$\S$ The $t$ test was used for comparisons.

|| The Tukey-Kramer test was used for comparisons.

placed in front of them to one of four pictures presented in a photographic booklet ${ }^{(19)}$. In a more recent study aiming to assess adolescents' perception of digital food pictures, $28 \%$ of participants selected the correct picture and $74 \%$ the correct or an adjacent one ${ }^{(22)}$. Baranowski et al. conducted a study among 120 children aged 8-13 years, who were asked to indicate which digital food images corresponded better to food models presenting foods commonly eaten by children in varying portion sizes ${ }^{(20)}$. Approximately $60 \%$ of foods were correctly classified and there were no differences in accuracy by the children's demographic characteristics.

In general, the food atlas used in the present study allows a valid perception of the quantity displayed. Difficulties in perception were noted for the amorphous salads, soups, vegetables and legumes (the latter commonly consumed in Greece as soups), traditional pies and savoury pastries, some pictures in the series of breakfast cereals and a traditional porridge (trahanas). Problems encountered in quantifying amorphous liquid dishes (such as soups, porridge and similar), as well as the limited capacity of young adults to estimate the quantity of vegetables and whole grains served on the plate, have also been reported by others ${ }^{(13,17,21-23,35)}$. The reduced ability to quantify the consumption of Greek traditional pies and pastries through food pictures has also been observed in a similar study among adolescents and adults ${ }^{(18)}$. According to the present study, if the pictures of 'vegetables and legumes' (including soups) were used in a survey setting they could lead to an underestimation of true intake, whereas the pictures of 'traditional pies and savoury pastries' could lead to an overestimation of intake.

Similarly to previous studies we have also observed a flat-slope phenomenon ${ }^{(17)}$, in which large portions tend to be underestimated and small ones overestimated, as well as that the smallest portions were more often correctly perceived than the largest ones ${ }^{(16,19,21,22)}$. This might reflect difficulties encountered by individuals in perceiving the volume of large portion sizes, or a general hesitation to select the largest portions. In our study, the perception of quantities presented in pictures was not related to personal characteristics, as deviations from the expected selections occurred irrespective of participants' gender, age, educational attainment, and number and age of offspring.

The present study aimed to identify errors introduced when individuals were asked to relate an amount of food displayed in reality to an amount presented in a photograph (perception), a process inherent in real-time data collections such as those of food diaries that are the recommended method for dietary assessment among children of this age ${ }^{(32)}$. Conceptualization and memory skills influence the accuracy of portion size estimations in dietary surveys based on recall methods ${ }^{(23)}$, which are preferentially applied in studies among adolescents and adults ${ }^{(32)}$. There is generally a lack of consensus on how to assess precision in portion size estimations and on how errors should be expressed so as to allow an objective interpretation of the findings ${ }^{(15,36)}$. Our study design, however, tried to replicate as closely as possible actual conditions, since it is highly improbable that participants will be presented with images showing the exact amount they consumed.

The present study was the first evaluating pictures of food portions consumed by young children in Greece and any background knowledge that could be useful in designing the study was limited to some small-scale, regional studies. However, when participants were asked to evaluate the appropriateness of the foods and recipes included in the atlas, more than half $(56 \%)$ of them indicated that the presented quantities reflected adequately 
the amount of food their offspring usually consumes and only $5 \%$ replied that the presented quantities correspond to occasional, infrequent consumption.

\section{Conclusion}

In conclusion, most parents and caregivers reported that it was easy to use the food atlas when reporting the intake of their offspring. In addition, the series of photographs included in the food atlas for infants, toddlers and children in Greece adequately assisted parents in perceiving the presented quantities, except from the picture series presenting amorphous, semi-liquid or liquid dishes, and pies or pastries with a filling. Since these types of foodstuffs (e.g. soups, porridges and soft pies) are commonly consumed in the first years of life, improved series should be developed for the presentation of these dishes or other quantification means need to be sought in large-scale surveys addressing very young children. Mobile phone applications, which are increasingly used in survey settings, can be particularly useful when assessing liquid and semi-liquid food items consumed by this population group. These applications make use of the phone camera and card to record consumption through sending digital images, while more advanced applications combine imaging with voice recording through which study participants can verbally describe aspects of their consumption. In addition, studies evaluating the performance of food pictures as quantification anchors should ensure the inclusion of several and various amorphous foods in their assessment, particularly since these items are commonly consumed by infants and young children.

\section{Acknowledgements}

Acknowledgements: The authors would like to thank P. Karathanassis and K. Tsiotas for their contribution in the realization of the photo atlas and the operationalization of the study. Financial support: This research received no specific grant from any funding agency in the public or commercial sector. It was supported by the not-for-profit Hellenic Health Foundation. Conflict of interest: None. Authorship: E.V., A.N., A.B. and A.T. were responsible for the conception and design of the study, and E.V., E.P., P.V. and A.B. were responsible for carrying it out. E.V., A.N. and M.K. were responsible for the analysis and interpretation of the data, and E.V. drafted the article. All authors revised the manuscript critically for important intellectual content and gave final approval of the version to be published. Ethics of human subject participation: This study was conducted according to the guidelines laid in the Declaration of Helsinki and all procedures involving human subjects were approved by the Hellenic Health Foundation Ethical Committee. Written informed consent was obtained from all subjects.

\section{References}

1. European Food Safety Authority (2011) Use of the EFSA comprehensive European food consumption database in exposure assessment. EFSA J 9, 2097-2130.

2. Foster E \& Adamson A (2014) Conference on "Childhood nutrition and obesity: current status and future challenges' Symposium 2: data collection challenges involved in measuring intake in early life: focus on methods. Proc Nutr Soc 73, 210-217.

3. European Food Safety Authority (2009) General principles for the collection of national food consumption data in the view of a pan-European dietary survey. EFSA J 7, 1435.

4. Merten C, Ferrari P, Bakker M et al. (2011) Methodological characteristics of the national dietary surveys carried out in the European Union as included in the European Food Safety Authority (EFSA) Comprehensive European Food Consumption Database. Food Addit Contam Part A Chem Anal Control Expo Risk Assess 28, 975-995.

5. Turconi G, Guarcello M, Berzolari FG et al. (2005) An evaluation of a colour food photography atlas as a tool for quantifying food portion size in epidemiological dietary surveys. Eur J Clin Nutr 59, 923-931.

6. Foster E, Matthews JN, Lloyd J et al. (2008) Children's estimates of food portion size: the development and evaluation of three portion size assessment tools for use with children. Br J Nutr 99, 175-184.

7. Robinson F, Morritz W, McGuiness P et al. (1997) A study of the use of a photographic food atlas to estimate served and self-served portion sizes. J Hum Nutr Diet 10, 117-124.

8. Foster E, Matthews JN, Nelson M et al. (2006) Accuracy of estimates of food portion size using food photographs - the importance of using age-appropriate tools. Public Health Nutr 9, 509-514.

9. Foster E, Adamson AJ, Anderson AS et al. (2009) Estimation of portion size in children's dietary assessment: lessons learnt. Eur J Clin Nutr 63, Suppl. 1, S45-S49.

10. Cypel YS, Guenther PM \& Petot GJ (1997) Validity of portion-size measurement aids: a review. J Am Diet Assoc 97, 289-292.

11. Faggiano F, Vineis P, Cravanzola D et al. (1992) Validation of a method for the estimation of food portion size. Epidemiology 3, 379-382.

12. Lucas F \& Niravong M (1995) Estimation of portion size using photographs: validity, strengths, weaknesses and recommendations. J Hum Nutr Diet 8, 65-74.

13. Venter CS, MacIntyre UE \& Vorster HH (2000) The development and testing of a food portion photograph book for use in an African population. J Hum Nutr Diet 13, 205-218.

14. Frobisher C \& Maxwell SM (2003) The estimation of food portion sizes: a comparison between using descriptions of portion sizes and a photographic food atlas by children and adults. J Hum Nutr Diet 16, 181-188.

15. Hernandez T, Wilder L, Kuehn D et al. (2006) Portion size estimation and expectation of accuracy. J Food Compost Anal 19, Suppl., S14-S21.

16. Ovaskainen ML, Pautri M, Reinivuo H et al. (2008) Accuracy in the estimation of food servings against the portions in food photographs. Eur J Clin Nutr 62, 674-681.

17. Subar AF, Crafts J, Zimmerman TP et al. (2010) Assessment of the accuracy of portion size reports using computer based food photographs aids in the development of an automated self-administered 24-hour recall. J Am Diet Assoc 110, 55-64.

18. Naska A, Valanou E, Peppa E et al. (2016) Evaluation of a digital food photography atlas used as portion size measurement aid in dietary surveys in Greece. Public Health Nutr 19, 2369-2376. 
19. Lillegaard ITL, Øverby NC \& Andersen LF (2005) Can children and adolescents use photographs of food to estimate portion sizes? Eur J Clin Nutr 59, 611-617.

20. Baranowski T, Baranowski JC, Watson KB et al. (2011) Children's accuracy of portion size estimation using digital food images: effects of interface design and size of image on computer screen. Public Health Nutr 14, 418-425.

21. Trolle E, Vandevijvere S, Ruprich J et al. (2013) Validation of a food quantification picture book targeting children of 0-10 years of age for pan-European and national dietary surveys. Br J Nutr 110, 2298-2308.

22. Vereecken C, Dohogne S, Covents M et al. (2010) How accurate are adolescents in portion-size estimation using the computer tool Young Adolescents' Nutrition Assessment on Computer (YANA-C)? Br J Nutr 103, 1844-1850.

23. Nelson M, Atkinson M \& Darbyshire S (1994) Food photography. I: the perception of food portion size from photographs. Br J Nutr 72, 649-663.

24. Nelson M, Atkinson M \& Darbyshire S (1996) Food photography II: use of food photographs for estimating portion size and the nutrient content of meals. Br J Nutr $\mathbf{7 6}$, 31-49.

25. Nelson M \& Haraldsdóttir J (1998) Food photographs: practical guidelines I. Design and analysis of studies to validate portion size estimates. Public Health Nutr 1, 219-230.

26. Nelson M \& Haraldsdóttir J (1998) Food photographs: practical guidelines II. Development and use of photographic atlases for assessing food portion size. Public Health Nutr 1, 231-237.

27. Foster E, Hawkins A, Simpson E et al. (2014) Developing an interactive portion size assessment system (IPSAS) for use with children. J Hum Nutr Diet 27, Suppl. 1, 18-25.

28. Conway JM, Ingwersen LA, Vinyard BT et al. (2003) Effectiveness of the US Department of Agriculture 5-step multiple-pass method in assessing food intake in obese and non-obese women. Am J Clin Nutr 77, 1171-1178.

29. Raper N, Perloff B, Ingwersen L et al. (2004) An overview of USDA's dietary intake system. J Food Compost Anal 17, 545-555.

30. Higgins JA, LaSalle AL, Zhaoxing P et al. (2009) Validation of photographic food records in children: are pictures really worth a thousand words? Eur J Clin Nutr 63, 1025-1033.

31. The PANCAKE Consortium (2012) External Scientific Report. PANCAKE - Pilot study for the Assessment of Nutrient intake and food Consumption Among Kids in Europe. Supporting Publications 2012:EN-339. http://www. efsa.europa.eu/sites/default/files/scientific_output/files/ main_documents/339e.pdf (accessed September 2016).

32. European Food Safety Authority, EFSA (2014) Guidance on the EU Menu methodology. EFSA J 12, 3944.

33. Johnson SL, Hughes SO, Cui X et al. (2014) Portion sizes for children are predicted by parental characteristics and the amounts parents serve themselves. Am J Clin Nutr 99, $763-770$.

34. Lawless HT \& Heymann H (1999) Sensory Evaluation of Food: Principles and Practices. Food Science Text Series. New York: Springer Science \& Business Media.

35. Nørnberg T.R, Houlby L, Jørgensen LN et al. (2014) Do we know how much we put on the plate? Assessment of the accuracy of self-estimated versus weighed vegetables and whole grain portions using an Intelligent Buffet at the FoodScape Lab. Appetite 81, 162-167.

36. De Keyzer W, Huybrechts I, De Maeyer M et al. (2011) Food photographs in nutritional surveillance: errors in portion size estimation using drawings of bread and photographs of margarine and beverages consumption. Br J Nutr 105, 1073-1083. 